\title{
Facile and Rapid Synthesis of Ultrafine PtPd Bimetallic Nanoparticles and Their High Performance toward Methanol Electrooxidation
}

\author{
Tiantian Xia, ${ }^{1}$ Hanrui Shen, ${ }^{1}$ Gang Chang, ${ }^{1}$ Yuting Zhang, \\ Honghui Shu, ${ }^{1}$ Munetaka Oyama, ${ }^{2}$ and Yunbin $\mathrm{He}^{1}$ \\ ${ }^{1}$ Hubei Collaborative Innovation Center for Advanced Organic Chemical Materials, Ministry of Education Key Laboratory for \\ the Green Preparation and Application of Functional Materials, Faculty of Materials Science and Engineering, Hubei University, \\ No. 368 Youyi Avenue, Wuchang, Wuhan 430062, China \\ ${ }^{2}$ Department of Material Chemistry, Graduate School of Engineering, Kyoto University, Nishikyo-ku, Kyoto 615-8520, Japan
}

Correspondence should be addressed to Gang Chang; gchanghubei@gmail.com and Yunbin He; yunbin.he@physik.uni-giessen.de Received 8 March 2014; Revised 30 June 2014; Accepted 15 July 2014; Published 4 August 2014

Academic Editor: Benxia Li

Copyright (c) 2014 Tiantian Xia et al. This is an open access article distributed under the Creative Commons Attribution License, which permits unrestricted use, distribution, and reproduction in any medium, provided the original work is properly cited.

Uniform and sub-10 nm size bimetallic PtPd nanoparticles (NPs) have been synthesized via a simple and facile method without using any surfactants at an ambient temperature. As a green and clean reductive agent, ascorbic acid (AA) was employed for the coreduction of $\mathrm{K}_{2} \mathrm{PtCl}_{4}$ and $\mathrm{K}_{2} \mathrm{PdCl}_{4}$ in aqueous solution. The morphology, composition, and structure of PtPd NPs had been characterized by transmission electron microscopy (TEM), field emission high resolution transmission electron microscopy (FE-HRTEM), energy dispersive spectroscopy (EDS), X-ray diffraction (XRD), and X-ray photoelectron spectroscope (XPS). Comparing with both the monometallic Pt and Pd, the as-prepared alloy nanoparticles show superior electrocatalytic activity and better tolerance against poisoning by intermediates generated during methanol electrooxidation, which makes them a promising electrocatalysts for direct methanol fuel cells (DMFCs). Meanwhile, the green and simple approach could be easily extended to the manufacture of bimetallic or trimetallic alloy nanomaterials.

\section{Introduction}

With the increasing depletion of fossil energy and the severity of environmental pollution, people pay great attention to develop a renewable, clean, and effective energy. A lot of research has been carried out extensively on the direct methanol fuel cells (DMFCs) due to their unique advantages, such as its high specific energy, environmental-friendly, and portability. The selection of anodic catalyst is extremely crucial for the performance of the DMFCs. Considering high catalytic activity and stabilized chemical properties, platinum is the most primary catalyst for the electrooxidation of low carbon-chain aliphatic alcohol such as methanol and ethanol in DMFCs $[1,2]$. Unfortunately, the application of Pt-based catalysts in DMFCs is severely hindered in commercial market because of the poor natural content of
Pt and poisoning effect with CO-like intermediates of the methanol electrooxidation [3]. Therefore, exploitation of new anodic catalysts in DMFCs is very important for improving the cell performance. It was verified that alloying Pt with inexpensive metals especially the transition metals can not only substantially reduce the cost of the electrocatalyst but also alter the geometrical and electronic effect to yield a more active catalytic surface [4]. Therefore, the research of bimetallic or trimetallic alloy nanomaterials has become a focal point in anodic electrocatalyst of DMFCs. [5-10]. Palladium, 50 times more abundant in nature and much cheaper than $\mathrm{Pt}$, is considered as an ideal substitution for the growth of the Pt-based bimetallic nanocatalysts owning to only $0.77 \%$ lattice mismatch with Pt. PtPd alloy nanomaterials exhibit a similar catalytic performance as well as a higher intermediate poison resistance compared with $\mathrm{Pt}$ 
during methanol electrooxidation [11, 12]. Thus, bimetallic PtPd nanocatalysts are expected to be a promising substitute for Pt catalysts in DMFCs.

So far, different kinds of methods for synthesizing PtPd bimetallic nanoparticles have been reported, such as waterin-oil technique, microwave irradiation [13], electroless deposition technique [14], normal wet impregnation technique, and flame aerosol [15]. Nevertheless, these methods are extremely difficult, complicated, and time-lavished. Kinds of organic solvents and/or surfactants are employed in most of the synthetic methods, which leads to environmental pollution $[16,17]$. Recently, lots of chemical reductants have been used to the fabrication of nanoparticles, such as hydrazine [18] and sodium borohydride, followed by toxicity, longtime thermal treatment, and even irretrievable damage to nanocrystals [19]. Consequently, it is imperative to seek a facile and surfactant-free process to fabricate bimetallic PtPd nanocrystals.

In this present work, we have developed a simple and rapid method to obtain the uniform and ultrafine PtPd NPs. The experiments were carried out in aqueous solution without any organic solvents or surfactant agents at an ambient temperature. It is worth noting that ascorbic acid is served as the reductant to reduce $\mathrm{K}_{2} \mathrm{PtCl}_{4}$ and $\mathrm{K}_{2} \mathrm{PdCl}_{4}$ simultaneously. The morphology and structure of the as-prepared PtPd nanoparticles were characterized by various techniques, including TEM, XRD, and XPS. Then, we examined and compared the electrocatalytic activity and tolerance of carbon black (Vulcan XC-72) supported bimetallic nanoparticles (PtPd NPs/V) with carbon black supported monometallic Pt and Pd NPs (Pt NPs/V, Pd NPs/V) toward methanol oxidation. The further electrochemical characterizations indicate superior electrocatalytic activity and poison tolerance of the prepared PtPd NPs/V for methanol oxidation compared with Pt NPs/V and Pd NPs/V, which indicates potential use of PtPd NPs/V as a new anode catalyst in DMFCs.

\section{Materials and Methods}

2.1. Chemicals. Vulcan XC-72 was obtained from Cabot Corp. $\mathrm{K}_{2} \mathrm{PtCl}_{4}$ and $\mathrm{K}_{2} \mathrm{PdCl}_{4}$ were purchased from Aldrich chem. Co. 5 wt $\%$ Nafion was produced by DuPont. Ascorbic acid and $\mathrm{KBr}$ were purchased from Sinopharm Chemical Reagent Co. All chemicals reagents were of analytical grade and used as received without further purification. All the aqueous solution was prepared with the ultrapure water which was produced from a Kertone Ultrapure Water System P60-CY (Kertone Water Treatment Co. Ltd., resistivity $>18 \mathrm{M} \Omega \cdot \mathrm{cm}$ ).

2.2. Instruments. XRD analysis of the as-synthesized samples was recorded on D8-advance diffractometer (Bruker, Germany) with a $\mathrm{Cu} K \alpha$ radiation source $(\lambda=0.15418 \mathrm{~nm})$. TEM (FEI TECNAI20, USA) and FE-HRTEM (JEM-2100F) were employed to characterize the morphology and sizes of the samples. EDS (JSM6510LV, Japan) was performed to determine the chemical composition of the catalysts. XPS were carried out using a SPeCS system (PHOIBOS 150, Germany) with $\mathrm{Al} \mathrm{K} \alpha$ radiation $(\mathrm{h} v=1486.6 \mathrm{eV})$. All electrochemical measurements were conducted using a 550 electrochemical workstation (Gaoss Union Instrument Company, China) at room temperature in a conventional three-electrode system which consisted of a $\mathrm{Pt}$ (wire) counter electrode and an $\mathrm{Ag} / \mathrm{AgCl}$ reference electrode. To remove dissolved oxygen, pure nitrogen gas was bubbled through the solution at the beginning of each experiment.

2.3. Preparation of $P t P d N P s / V, P t N P s / V$, and $P d N P s / V$. In a typical synthesis, $160 \mu \mathrm{L}$ of $100 \mathrm{mM} \mathrm{K}_{2} \mathrm{PtCl}_{4}$ and $40 \mu \mathrm{L}$ of $100 \mathrm{mM} \mathrm{K}_{2} \mathrm{PdCl}_{4}$ were dispersed in $100 \mathrm{~mL}$ ultrapure water which contained $3 \mathrm{mg} \mathrm{KBr}$. After adjusting the mixed solution $\mathrm{pH}$ to $2.18,1 \mathrm{~mL}$ of $60 \mathrm{mM}$ ascorbic acid was added into the solution with constant stirring for 30 minutes. After that, $14.7 \mathrm{mg}$ Vulcan XC-72 was dispersed into the as-prepared brown suspension while keeping durative sonication for $1 \mathrm{~h}$ and magnetic stirring for $5 \mathrm{~h}$. All of the operations were taking place at room temperature. The PtPd NPs/V was ultimately obtained after centrifugation, washing, and drying at $60^{\circ} \mathrm{C}$ in a vacuum oven for overnight. For comparison, the monometallic Pt NPs/V and Pd NPs/V were also prepared in the same way with that of PtPd NPs/V except only adding $0.2 \mathrm{~mL}$ of $100 \mathrm{mM} \mathrm{K}_{2} \mathrm{PtCl}_{4}$ or $0.2 \mathrm{~mL}$ of $100 \mathrm{mM} \mathrm{K}_{2} \mathrm{PdCl}_{4}$ as metal precursor, respectively.

2.4. Preparation of Working Electrode. The procedure of preparing modified working electrodes consulted some previous reports $[15,16,20]$. First of all, the glassy carbon (GC) electrode must ensure being polished to a mirror finish by using slurry of $1,0.3$, and $0.05 \mu \mathrm{m}$ alumina powers, washing via ultrasonic in ethanol and ultrapure water for 3 minutes, and then drying under nitrogen steam. Afterwards, $2 \mathrm{mg}$ of the nanocatalysts loaded Vulcan XC-72 was distributed into a mixture of ultrapure water $(0.9 \mathrm{~mL})$ and $0.1 \mathrm{~mL}$ of Nafion (5 wt.\%) and then using ultrasonic treatment to form a homogeneous black suspension. Finally, $5 \mu \mathrm{L}$ of the uniform suspension was laid on the surface of the GC electrode and dried at an ambient temperature.

\section{Result and Discussion}

3.1. Morphology and Structural Characterization of PtPd NPs/ $V$. To investigate the alloy nature and crystalline structure, the as-synthesized PtPd NPs/V, Pt NPs/V, and Pd NPs/V were characterized by XRD measurements. The XRD patterns of Pd NPs/V, PtPd NPs/V, and Pt NPs/V catalysts were shown in Figure 1. Both Pt NPs/V and Pd NPs/V exhibit diffraction peaks of (111), (200), and (220) planes, respectively, corresponding to the standard data of Pt (JCPDS no. 04-0802) and Pd (JCPDS no. 46-1043) [21, 22]. These demonstrate that the crystal structures of monometallic catalysts are face-centered cubic structure (fcc). Similarly, the peaks at the $2 \theta$ value of $39.92^{\circ}, 46.22^{\circ}$, and $67.74^{\circ}$ in the pattern of PtPd NPs/V are attributed to (111), (200), and (220) crystal planes for the fcc structure of PtPd. All the peak positions of PtPd NPs/V are found to be slightly shifted to high diffraction angles compared with that of $\mathrm{Pt} \mathrm{NPs} / \mathrm{V}$. Taking an example of the (111) plane diffraction peak, the $2 \theta$ value of PtPd NPs/V planes 


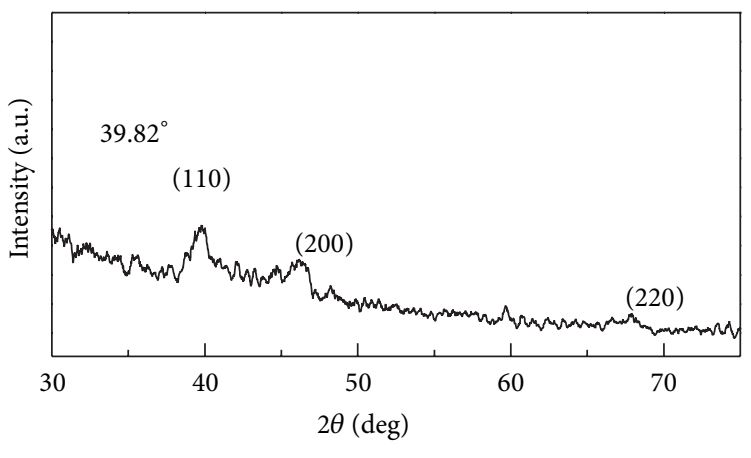

Pt NPs/V

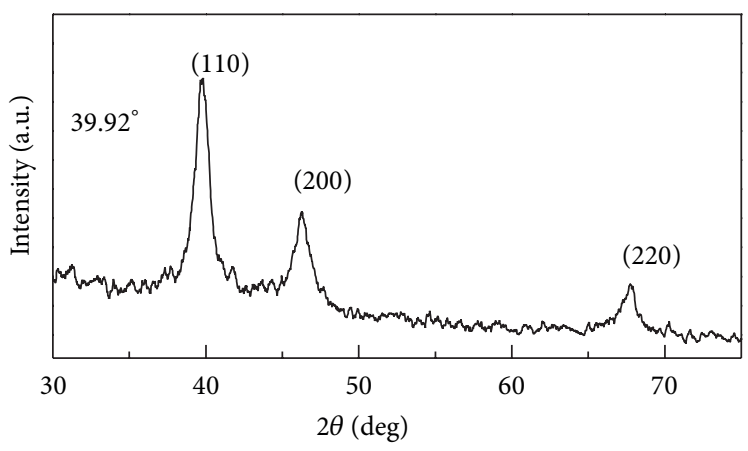

— PtPd NPs/V

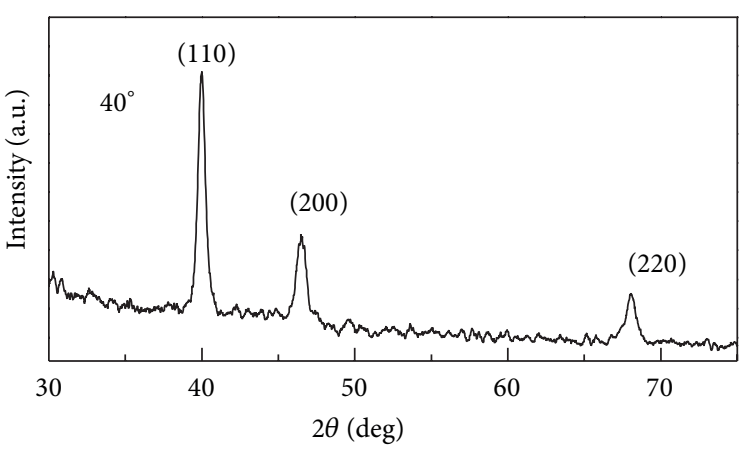

Pd NPs/V

FIgURE 1: XRD patterns of Pt NPs/V, PtPd NPs/V, and Pd NPs/V nanocomposites.

$\left(39.92^{\circ}\right)$ is between those of Pt NPs/V $\left(39.82^{\circ}\right)$ and Pd NPs/V $\left(40^{\circ}\right)$. These results were attributed to the addition of $\mathrm{Pd}$ to the $\mathrm{Pt}$ for the difference in atomic size $(\mathrm{Pd}<\mathrm{Pt})[23]$. Hence, it is an indication that PtPd alloy nanoparticles have been successfully synthesized $[24,25]$.

The TEM and HRTEM images of the bimetallic PtPd nanoparticles before and after loading on Vulcan XC-72 are shown in Figure 2. Figures 2(a) and 2(b) are the images of PtPd alloy nanoparticles before loading on Vulcan XC-72 at different magnification. Well-dispersed PtPd alloy nanoparticles were observed with the average size $7 \mathrm{~nm}$ through the statistics of TEM image. No visible aggregation was found. For PtPd NPs/V (Figure 2(c)), the PtPd nanoparticles are uniformly dispersed on Vulcan XC-72 and the original morphology of nanoparticles basically remained.
The HRTEM image of PtPd NPs/V (Figure 2(d)) shows wellresolved continuous fringes in the same direction. The interval between the two lattice fringes was found to be $0.225 \mathrm{~nm}$, which is between 0.2265 and $0.2246 \mathrm{~nm}$, corresponding to the $\{111\}$ interplanar distance of $\mathrm{fcc} P t$ and $\mathrm{Pd}$, respectively, indicating the formation of PtPd alloy nanostructures. These TEM results demonstrated that well-dispersed PtPd alloy nanoparticles have been successfully synthesized and could be loaded onto carbon black (Vulcan XC-72) for further application in DMFC.

To further characterize the alloy nature of the as-synthesised nanocrystals, PtPd nanoparticles were investigated by EDS (Table 1), revealing the presence of $\mathrm{C}, \mathrm{Pt}$, and $\mathrm{Pd}$. The bulk composition estimates the ratio of $\mathrm{Pt}$ and $\mathrm{Pd}$ is $4: 3$ which is deviated from the nominal ratio ( $\mathrm{Pt}: \mathrm{Pd} 4: 1)$. This 


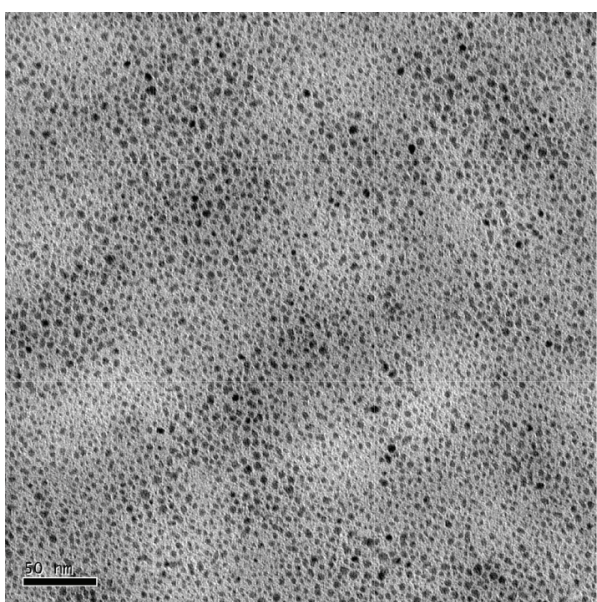

(a)

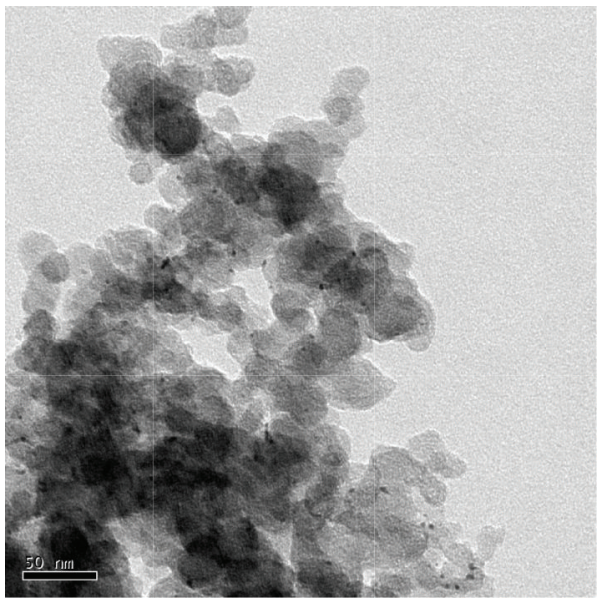

(c)

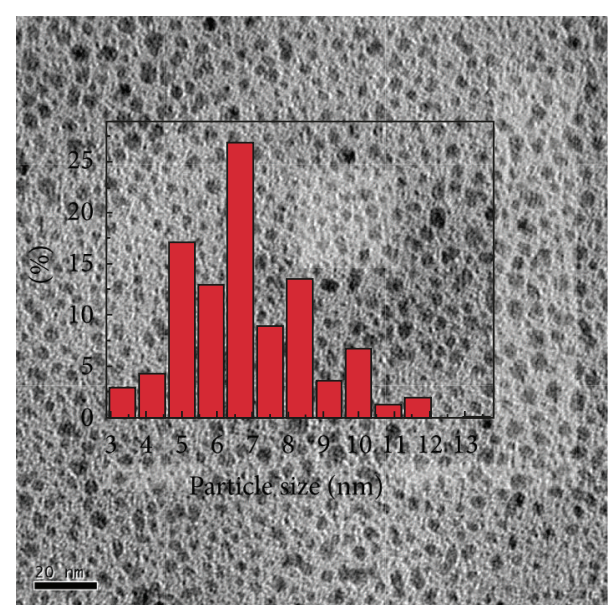

(b)

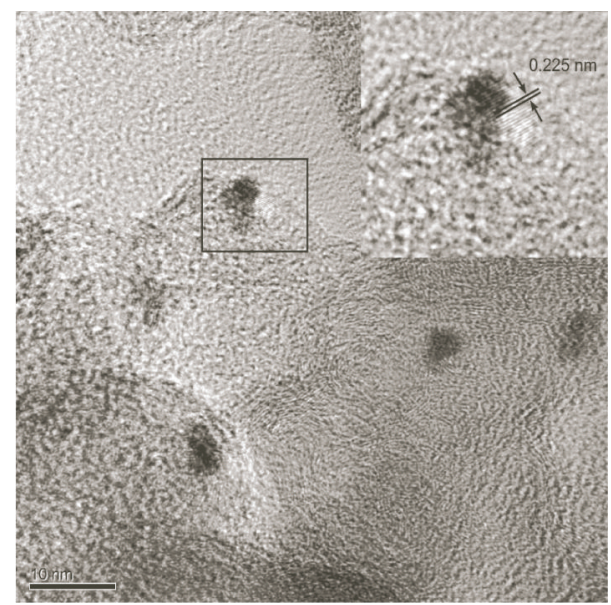

(d)

Figure 2: TEM images of PtPd NPs ((a), (b)) and PtPd NPs/V (c); the inset in (b) is the distribution of particle size; HRTEM image of PtPd NPs/V (d); the inset in (d) is the enlarged figure of the selected area. The scale bars are $50 \mathrm{~nm}(\mathrm{a}), 20 \mathrm{~nm}(\mathrm{~b}), 50 \mathrm{~nm}(\mathrm{c})$, and $10 \mathrm{~nm}(\mathrm{~d})$.

TABLE 1: The ratio of $\mathrm{Pt} / \mathrm{Pd}$ and the mass percentage of $\mathrm{PtPd}$, Pt and $\mathrm{Pd}$ in PtPd NPs/V, Pt NPs/V, Pd NPs/V were measured by EDS.

\begin{tabular}{lcccc}
\hline $\begin{array}{l}\text { Nominal } \\
\text { Ratio } \\
(\mathrm{Pt}: \text { Pd) }\end{array}$ & $\begin{array}{c}\text { Measure by } \\
\text { EDS }: \text { Pd) }\end{array}$ & $\begin{array}{c}\text { PtPd mass } \\
\text { percentage }\end{array}$ & $\begin{array}{c}\text { Pt mass } \\
\text { percentage }\end{array}$ & $\begin{array}{r}\text { Pd mass } \\
\text { percentage }\end{array}$ \\
\hline $4: 1$ & $1.4: 1$ & $4.775 \%$ & $2.137 \%$ & $6.294 \%$ \\
\hline
\end{tabular}

result should be able to consider the different banding energy of Pt and Pd relative to the supports [26].

XPS was employed to study the surface elemental composition of the nanocomposites as shown in Figure 3. Figures 3(a) and 3(b) show the Pt 4f and Pd 3d spectra of the sample, respectively. As for $\mathrm{Pt} 4 \mathrm{f}$, it can be observed two peaks at 71.15 and $74.45 \mathrm{eV}$ corresponding to $\mathrm{Pt} 4 \mathrm{f}_{7 / 2}$ and $\mathrm{Pt} 4 \mathrm{f}_{5 / 2}$, which further confirms the existence of Pt metal. Similarly, the binding energy at 335.35 and $340.85 \mathrm{eV}$ corresponds to metallic Pd $3 \mathrm{~d}_{5 / 2}$ and $\mathrm{Pd} 3 \mathrm{~d}_{3 / 2}$ in Figure $3(\mathrm{~b})$, respectively. Therefore, it can be concluded that the $\mathrm{Pd}^{\mathrm{II}}$ and $\mathrm{Pd}^{\mathrm{II}}$ precursors have been successfully reduced by AA in our synthesis and the PtPd alloy has been formed $[27,28]$.

3.2. Electrochemical Investigation of the PtPd NPs/V and Monometallic Pt, $P d N P s / V$. Typical cyclic voltammograms (CV) of the PtPd NPs/V and metallic Pt NPs/V, Pd NPs/V modified glassy carbon electrodes were measured in $\mathrm{N}_{2}$ saturated $0.5 \mathrm{M} \mathrm{H}_{2} \mathrm{SO}_{4}$ at a potential between $-0.2 \mathrm{~V}$ and $1.2 \mathrm{~V}$ with a scan rate of $100 \mathrm{mV} / \mathrm{s}$ (Figure 4). In the potential region of $-0.2 \mathrm{~V}$ to $0.2 \mathrm{~V}$, the typical hydrogen adsorption and desorption peaks are observed, which is a dominant factor for the estimation of the electrochemically active surface area (ECSA). The ECSA value can be evaluated by $Q_{H} /$ $(210 \times L)$ [29]. Among this formula, $Q_{H}$ is the total electric charge of hydrogen adsorption and desorption on the PtPd nanoparticles, which can be calculated by integrating the area under the CV curve in the hydrogen adsorption range after a double-layer correction. The charge of each actual active area is $210 \mu \mathrm{C} \mathrm{cm}^{-2}[11,30] . L$ is the catalyst loading on the glassy carbon surface (in mg). Therefore, it is assumed 


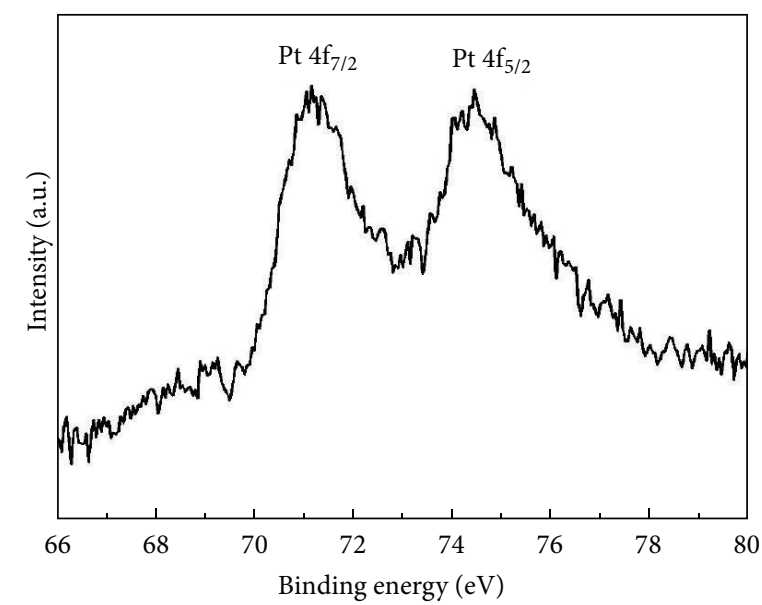

(a)

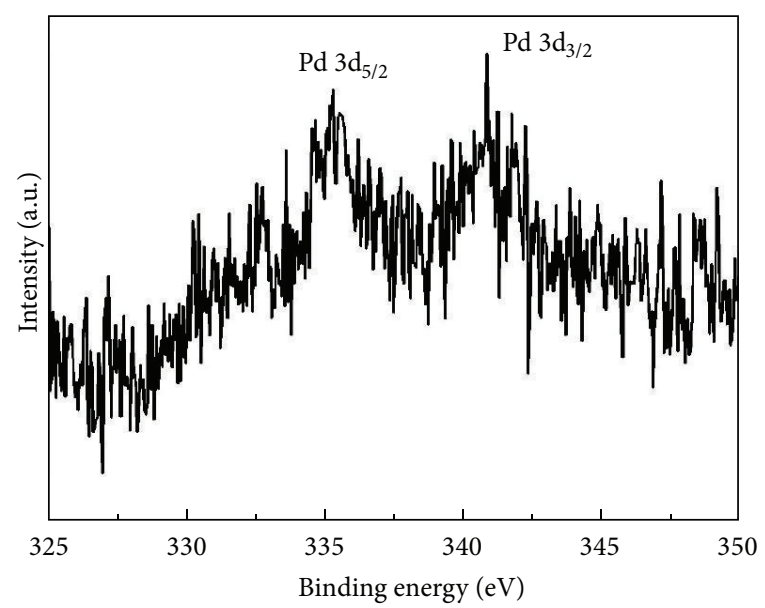

(b)

Figure 3: Fine-scan XPS spectra of Pd 4f (a) and Pd 3d (b) of the PtPd NPs/V composite.

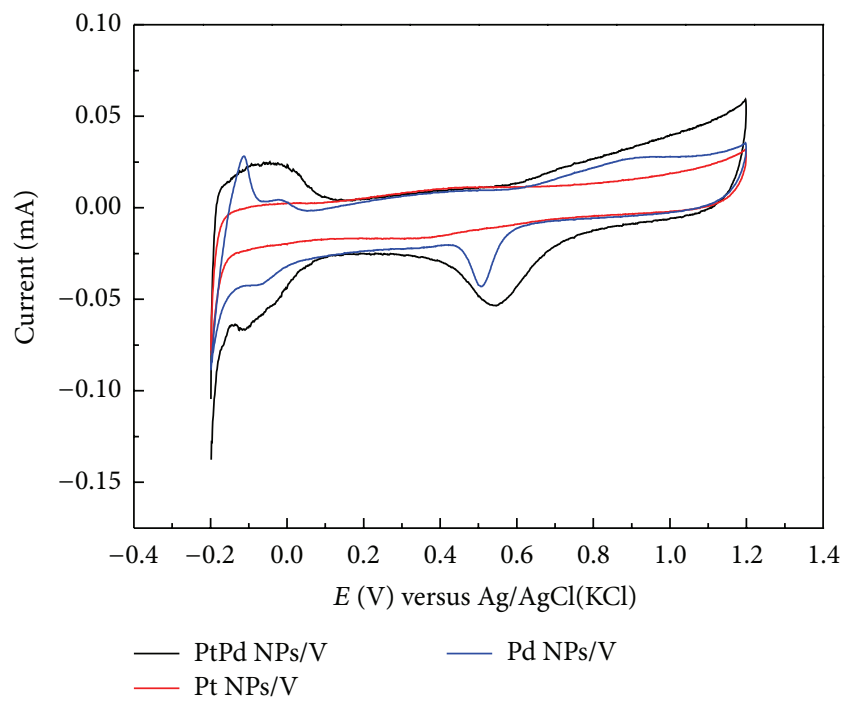

Figure 4: Cyclic voltammograms of PtPd NPs/V, Pt NPs/V, and Pd $\mathrm{NPs} / \mathrm{V}$ in nitrogen saturated solutions of $0.5 \mathrm{M} \mathrm{H}_{2} \mathrm{SO}_{4}$ at a scan rate of $100 \mathrm{mV} \mathrm{s}^{-1}$.

that the ECSA of PtPd NPs/V, Pt NPs/V, and Pd NPs/V is $60.40 \mathrm{~m}^{2} \mathrm{~g}^{-1}, 11.58 \mathrm{~m}^{2} \mathrm{~g}^{-1}$, and $10.56 \mathrm{~m}^{2} \mathrm{~g}^{-1}$, respectively. In comparison with Pt NPs/V and Pd NPs/V, PtPd NPs/V shows obviously higher ECSA value, which confirms the excellent electrooxidation toward methanol.

3.3. Electrocatalytic Properties of PtPd NPs/V and Monometallic Pt, Pd NPs/V for the Oxidation of Methanol. The CV tests in Figure 5 show the electrocatalytic activities of PtPd NPs/G and metallic Pt NPs/V, Pd NPs/V for the oxidation of methanol. $\mathrm{CV}$ behavior of the samples was carried out preliminarily in $\mathrm{N}_{2}$-saturated $1.0 \mathrm{M} \mathrm{NaOH}$ containing $0.5 \mathrm{M}$

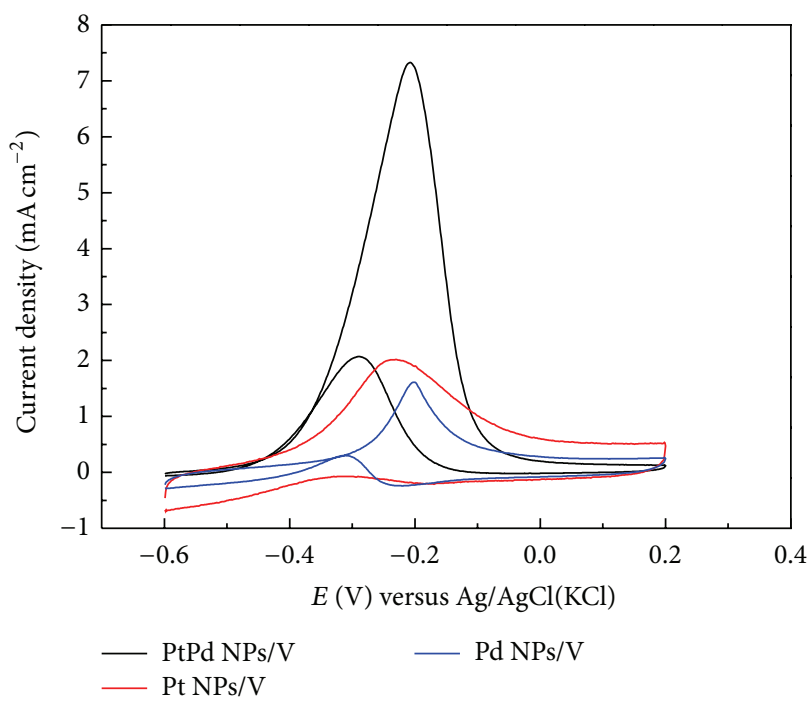

Figure 5: Cyclic voltammograms of PtPd NPs/V, Pt NPs/V, and $\mathrm{Pd} \mathrm{NPs/V} \mathrm{measured} \mathrm{in} \mathrm{nitrogen} \mathrm{saturated} \mathrm{solutions} \mathrm{of} 1.0 \mathrm{M} \mathrm{NaOH}$ containing $0.5 \mathrm{M} \mathrm{CH}_{3} \mathrm{OH}$ at a scan rate of $100 \mathrm{mV} \mathrm{s}^{-1}$.

$\mathrm{CH}_{3} \mathrm{OH}$ during the potential of -0.6 and $0.2 \mathrm{~V}$ (versus $\mathrm{Ag} / \mathrm{AgCl}$ ). The scan rate was kept at $100 \mathrm{mV} / \mathrm{s}$.

After normalization by ECSAs, we can observe the characteristic anodic peaks in the forward sweeps and the cathode peaks in the reverse sweeps at $\sim-0.2 \mathrm{~V}$ and $\sim-0.3 \mathrm{~V}$, respectively. It is clear to view that the maximum current density of PtPd NPs/V $\left(7.326 \mathrm{~mA} \mathrm{~cm}^{-2}\right)$ is much larger than that of monometallic Pt NPs/V $\left(2.018 \mathrm{~mA} \mathrm{~cm}^{-2}\right)$ and Pd NPs/ $\mathrm{V}\left(1.611 \mathrm{~mA} \mathrm{~cm}^{-2}\right)$. Moreover, the onset potential of PtPd NPs/V for methanol electrooxidation reaction (MOR) has an obvious negative shift compared with those of Pt NPs/V and $\mathrm{Pd} \mathrm{NPs} / \mathrm{V}$, which presents the superior catalytic performance of PtPd bimetallic to some degree. Furthermore, the value of 


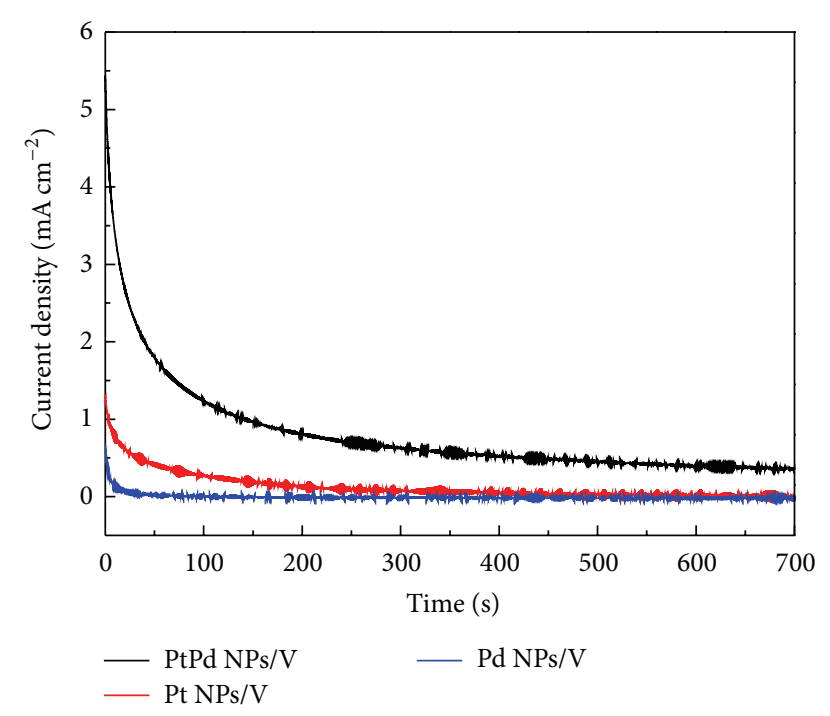

FIgURE 6: Chronoamperometry curves of PtPd NPs/V, Pt NPs/V, and $\mathrm{Pd} \mathrm{NPs} / \mathrm{V}$ measured in nitrogen saturated solutions of $1.0 \mathrm{M}$ $\mathrm{NaOH}$ containing $0.5 \mathrm{M} \mathrm{CH}_{3} \mathrm{OH}$ at a scan rate of $100 \mathrm{mV} \mathrm{s}^{-1}$.

the ratio $\left(i_{f} / i_{b}\right)$ of the forward peak current density $\left(i_{f}\right)$ to the reverse peak current density $\left(i_{b}\right)$ is a crucial index in the MOR for appraising the poison tolerance to CO-like intermediate. Studies have shown that a higher value of $i_{f} / i_{b}$ indicates the better effect of tolerating poisoning species toward MORs $[4,11]$. The $i_{f} / i_{b}$ value of the PtPd NPs/V catalysts (3.51) is higher than that of monometallic Pt NPs/V, Pd NPs/V catalysts (2.50), implying that the bimetallic catalysts have a much better poison tolerance. The immensely enhanced electrocatalytic activity and poisoning tolerance for MOR should give the credit to the "bifunctional catalysts" effect [31]. It is considered that the alloy has decreased the distance of PtPd bond and increased the vacancy of Pt d-electron, obtaining a more active catalytic surface [11].

To study the long-term stability of the PtPd NPs/V toward MOR, chronoamperometry tests were conducted for $700 \mathrm{~s}$ at room temperature (Figure 6). In the view of curves in IT, 20 s later, the initial current density rapidly decreased to almost $1 / 2$; hereafter, the curves begin to flatten. This result is due to the formation of poisonous intermediate species during MOR, such as $\mathrm{CO}_{\mathrm{ads}}$ [1], $\mathrm{CH}_{3} \mathrm{OH}_{\mathrm{ads}}$, and $\mathrm{CHO}_{\mathrm{ads}}$ [15], attached on the surface of the catalysts. The intermediate species adsorbed onto the catalysts will block the activation sites and refrain from the oxidation of methanol. However, a higher current density of PtPd NPs/V $\left(5.44 \mathrm{~mA} \mathrm{~cm}^{-2}\right)$ was found compared with Pt NPs/V $\left(1.29 \mathrm{~mA} \mathrm{~cm}^{-2}\right)$ and Pd $\mathrm{NPs} / \mathrm{V}\left(0.68 \mathrm{~mA} \mathrm{~cm}^{-2}\right)$, which means the numerous active sites available on the surface of the PtPd nanocatalysts, further indicating the better electrocatalytic activity of bimetallic PtPd. This result can also be understood mainly based on the synergistic interaction of Pt and Pd in the catalysts [4]. As shown in Figure 6, the current density of PtPd NPs/V is obviously lager than that of Pt NPs/V and Pd NPs/V along the time range, which means the bimetallic catalyst possesses much better poison tolerance during the electrochemical oxidation of methanol.

\section{Conclusion}

In this present work, we successfully fabricated uniform and sub-10 nm bimetallic PtPd nanocrystals by a clean and facile method in aqueous solution at ambient temperature, in which ascorbic acid act as soft and green reductant. The as-synthesised PtPd NPs/V shows great catalytic activity and super poisoning tolerance for MOR in alkaline media than those of monometallic Pt NPs/V and Pd NPs/V. This facile method is also versatile for preparing the other bimetallic or trimetallic alloy nanoparticles as new electrocatalyst for the application in fuel cell.

\section{Conflict of Interests}

The authors declare that there is no conflict of interests regarding the publication of this paper.

\section{Acknowledgments}

This investigation was supported by the National Natural Science Foundation of China (nos. 51102085, 61274010), Program for New Century Excellent Talents in University, Ministry of Education of China (NCET-09-0135), Natural Science Foundation of Hubei Province (nos. 2011CDB057, 2011CDA81), and Science Foundation from Hubei Provincial Department of Education (no. Q20111002).

\section{References}

[1] O. Winjobi, Z. Zhang, C. Liang, and W. Li, "Carbon nanotube supported platinum-palladium nanoparticles for formic acid oxidation," Electrochimica Acta, vol. 55, no. 13, pp. 4217-4221, 2010.

[2] Y. W. Lee, M. Kim, Y. Kim, S. W. Kang, J. Lee, and S. W. Han, "Synthesis and electrocatalytic activity of Au-Pd alloy nanodendrites for ethanol oxidation," The Journal of Physical Chemistry C, vol. 114, no. 17, pp. 7689-7693, 2010.

[3] Y. Zhang, H. Shu, G. Chang et al., "Facile synthesis of palladiumgraphene nanocomposites and their catalysis for electrooxidation of methanol and ethanol," Electrochimica Acta, vol. 109, pp. 570-576, 2013.

[4] Y. Hu, P. Wu, H. Zhang, and C. Cai, "Synthesis of graphenesupported hollow Pt-Ni nanocatalysts for highly active electrocatalysis toward the methanol oxidation reaction," Electrochimica Acta, vol. 85, pp. 314-321, 2012.

[5] A. X. Yin, X. Q. Min, Y. W. Zhang, and C. H. Yan, "Shapeselective synthesis and facet-dependent enhanced electrocatalytic activity and durability of monodisperse Sub-10 nm PtPd tetrahedrons and cubes," Journal of the American Chemical Society, vol. 133, no. 11, pp. 3816-3819, 2011.

[6] J. Wang, D. F. Thomas, and A. Chen, "Nonenzymatic electrochemical glucose sensor based on nanoporous PtPb networks," Analytical Chemistry, vol. 80, no. 4, pp. 997-1004, 2008. 
[7] X. Li, X. Wang, S. Song, D. Liu, and H. Zhang, "Selectively deposited noble metal nanoparticles on $\mathrm{Fe}_{3} \mathrm{O}_{4}$ /graphene composites: stable, recyclable, and magnetically separable catalysts," Chemistry, vol. 18, no. 24, pp. 7601-7607, 2012.

[8] R. Ojani, J. B. Raoof, and E. Hasheminejad, "One-step electroless deposition of $\mathrm{Pd} / \mathrm{Pt}$ bimetallic microstructures by galvanic replacement on copper substrate and investigation of its performance for the hydrogen evolution reaction," International Journal of Hydrogen Energy, vol. 38, no. 1, pp. 92-99, 2013.

[9] M. Giovanni, H. L. Poh, A. Ambrosi et al., "Noble metal (Pd, Ru, $\mathrm{Rh}, \mathrm{Pt}, \mathrm{Au}, \mathrm{Ag}$ ) doped graphene hybrids for electrocatalysis," Nanoscale, vol. 4, no. 16, pp. 5002-5008, 2012.

[10] V. L. Nguyen, M. Ohtaki, T. Matsubara, M. T. Cao, and M. Nogami, "New experimental evidences of Pt-Pd bimetallic nanoparticles with core-shell configuration and highly fineordered nanostructures by high-resolution electron transmission microscopy," Journal of Physical Chemistry C, vol. 116, no. 22, pp. 12265-12274, 2012.

[11] X. Yang, Q. Yang, J. Xu, and C. Lee, “Bimetallic PtPd nanoparticles on Nafion-graphene film as catalyst for ethanol electrooxidation," Journal of Materials Chemistry, vol. 22, no. 16, pp. 8057-8062, 2012.

[12] M. Jiang, B. Lim, J. Tao et al., "Epitaxial overgrowth of platinum on palladium nanocrystals," Nanoscale, vol. 2, no. 11, pp. 24062411, 2010.

[13] Y. Lin, D. W. Baggett, J. Kim, E. J. Siochi, and J. W. Connell, "Instantaneous formation of metal and metal oxide nanoparticles on carbon nanotubes and graphene via solvent-free microwave heating," ACS Applied Materials and Interfaces, vol. 3, no. 5, pp. 1652-1664, 2011.

[14] C. Huang, N. Pu, C. Wang, J. Huang, Y. Sung, and M. Ger, "Hydrogen storage in graphene decorated with Pd and Pt nanoparticles using an electroless deposition technique," Separation and Purification Technology, vol. 82, no. 1, pp. 210-215, 2011.

[15] Y. Xu and X. Lin, "Facile fabrication and electrocatalytic activity of Pt0.9Pd0.1 alloy film catalysts," Journal of Power Sources, vol. 170, no. 1, pp. 13-19, 2007.

[16] Y. Qin, X. Zhang, J. Wang, and L. Wang, "Rapid and shape-controlled synthesis of "clean" star-like and concave Pd nanocrystallites and their high performance toward methanol oxidation," Journal of Materials Chemistry, vol. 22, no. 30, pp. 14861-14863, 2012.

[17] S. Moussa, V. Abdelsayed, and M. Samy El-Shall, "Laser synthesis of $\mathrm{Pt}, \mathrm{Pd}, \mathrm{CoO}$ and $\mathrm{Pd}-\mathrm{CoO}$ nanoparticle catalysts supported on graphene," Chemical Physics Letters, vol. 510, no. 4-6, pp. 179-184, 2011.

[18] P. Zhou, Z. Dai, M. Fang, X. Huang, J. Bao, and J. Gong, "Novel dendritic palladium nanostructure and its application in biosensing," Journal of Physical Chemistry C, vol. 111, no. 34, pp. 12609-12616, 2007.

[19] S. Kim, G. H. Jeong, D. Choi et al., "Synthesis of noble metal/graphene nanocomposites without surfactants by one-step reduction of metal salt and graphene oxide," Journal of Colloid and Interface Science, vol. 389, no. 1, pp. 85-90, 2013.

[20] G. Fu, K. Wu, J. Lin et al., "One-pot water-based synthesis of Pt$\mathrm{Pd}$ alloy nanoflowers and their superior electrocatalytic activity for the oxygen reduction reaction and remarkable methanoltolerant ability in acid media," The Journal of Physical Chemistry C, vol. 117, no. 19, pp. 9826-9834, 2013.
[21] Y. Piao, Y. Jang, M. Shokouhimehr, I. S. Lee, and T. Hyeon, "Facile aqueous-phase synthesis of uniform palladium nanoparticles of various shapes and sizes," Small, vol. 3, no. 2, pp. 255-260, 2007.

[22] R. Yue, C. Wang, F. Jiang et al., "Electrocatalytic oxidation of formic acid on $\mathrm{Pt}-\mathrm{Pd}$ decorated polyfluorenes with hydroxyl and carboxyl substitution," International Journal of Hydrogen Energy, vol. 38, no. 29, pp. 12755-12766, 2013.

[23] J. Datta, A. Dutta, and S. Mukherjee, "The beneficial role of the cometals Pd and Au in the carbon-supported PtPdAu catalyst toward promoting ethanol oxidation kinetics in alkaline fuel cells: temperature effect and reaction mechanism," The Journal of Physical Chemistry C, vol. 115, no. 31, pp. 15324-15334, 2011.

[24] W. He, H. Jiang, Y. Zhou et al., "An efficient reduction route for the production of Pd-Pt nanoparticles anchored on graphene nanosheets for use as durable oxygen reduction electrocatalysts," Carbon, vol. 50, no. 1, pp. 265-274, 2012.

[25] H. Li, G. Sun, N. Li, S. Sun, D. Su, and Q. Xin, "Design and preparation of highly active $\mathrm{Pt}-\mathrm{Pd} / \mathrm{C}$ catalyst for the oxygen reduction reaction," The Journal of Physical Chemistry C, vol. 111, no. 15, pp. 5605-5617, 2007.

[26] J. Russell, P. Zapol, P. Král, and L. A. Curtiss, "Methane bond activation by $\mathrm{Pt}$ and $\mathrm{Pd}$ subnanometer clusters supported on graphene and carbon nanotubes," Chemical Physics Letters, vol. 536, pp. 9-13, 2012.

[27] G. Fu, L. Tao, M. Zhang et al., "One-pot, water-based and highyield synthesis of tetrahedral palladium nanocrystal decorated graphene," Nanoscale, vol. 5, no. 17, pp. 8007-8014, 2013.

[28] S. S. Mahapatra, A. Dutta, and J. Datta, "Temperature dependence on methanol oxidation and product formation on $\mathrm{Pt}$ and Pd modified Pt electrodes in alkaline medium," International Journal of Hydrogen Energy, vol. 36, no. 22, pp. 14873-14883, 2011.

[29] N. V. Long, T. D. Hien, T. Asaka, M. Ohtaki, and M. Nogami, "Synthesis and characterization of Pt-Pd alloy and core-shell bimetallic nanoparticles for direct methanol fuel cells (DMFCs): enhanced electrocatalytic properties of well-shaped coreshell morphologies and nanostructures," International Journal of Hydrogen Energy, vol. 36, no. 14, pp. 8478-8491, 2011.

[30] M. Shao, J. H. Odell, S. Choi, and Y. Xia, "Electrochemical surface area measurements of platinum- and palladium-based nanoparticles," Electrochemistry Communications, vol. 31, pp. 46-48, 2013.

[31] S. Motoo, M. Shibata, and M. Watanabe, "Electrocatalysis by adatoms. Part VI. Enhancement of CO oxidation on Pt(subs) and $\mathrm{Pt}-\mathrm{Au}$ (subs) electrodes by $\mathrm{Sn}$ ad-atoms," Journal of Electroanalytical Chemistry, vol. 110, no. 1-3, pp. 103-109, 1980. 

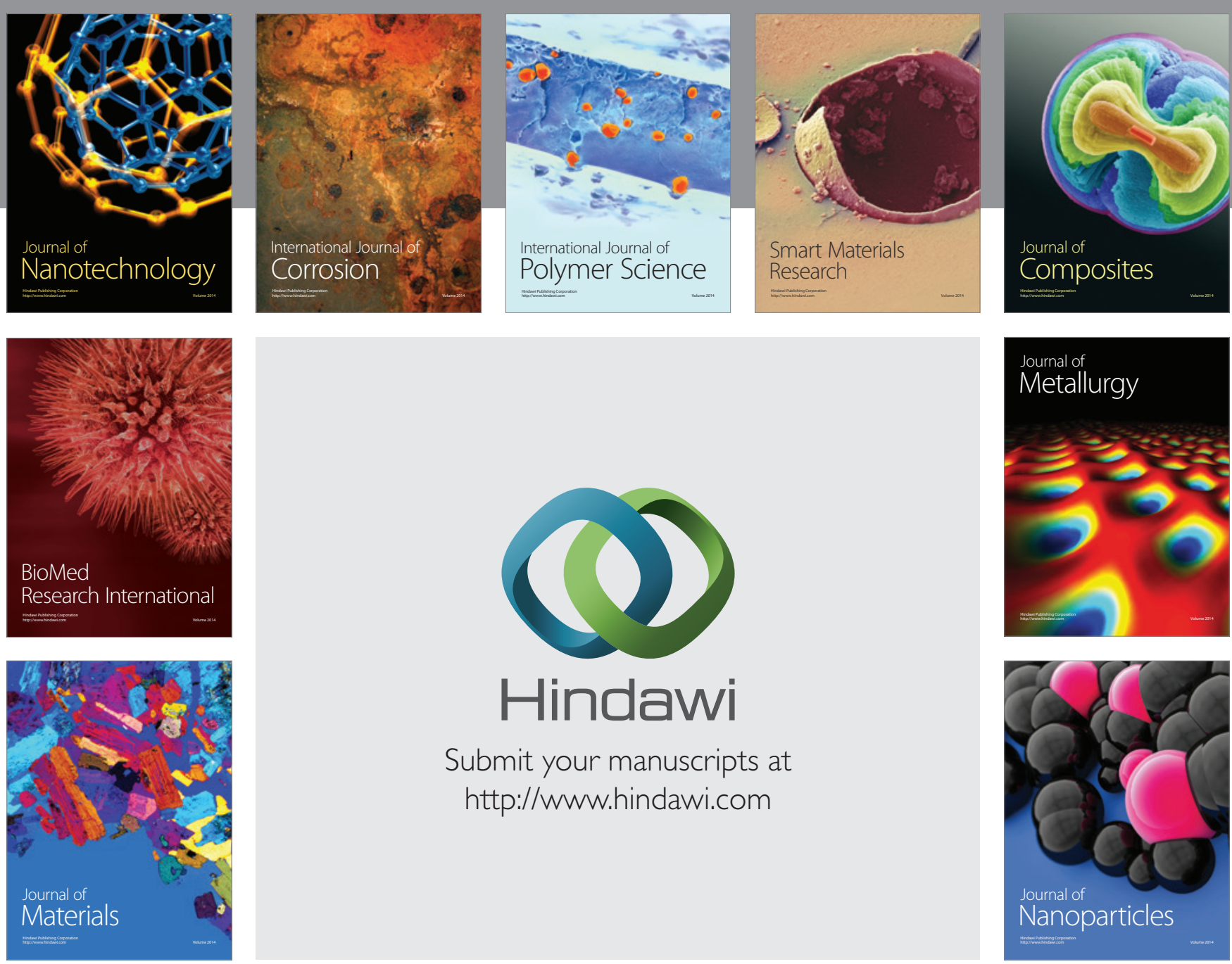

Submit your manuscripts at http://www.hindawi.com
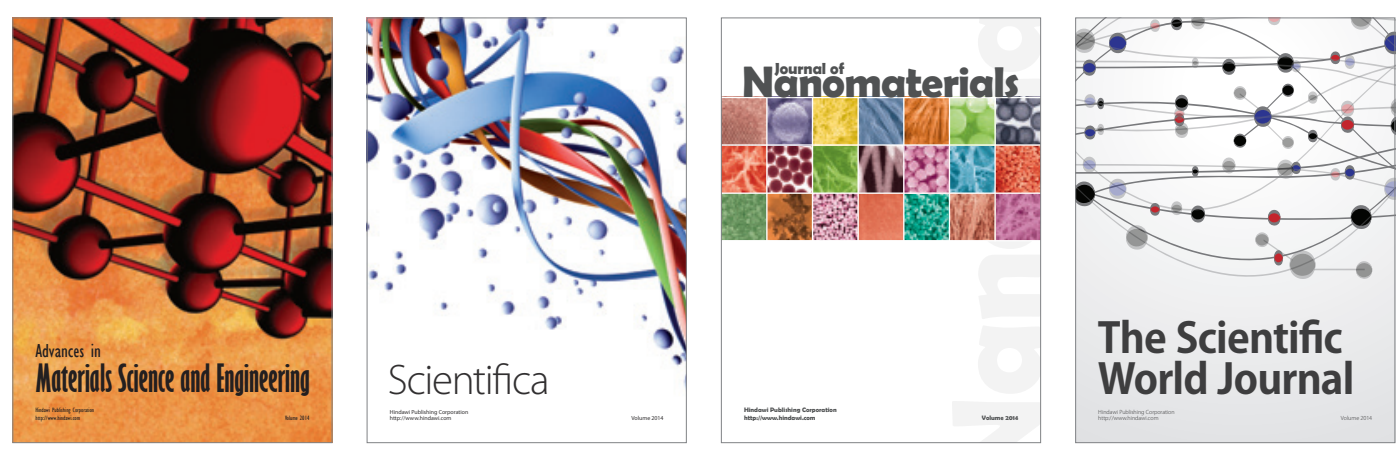

\section{The Scientific World Journal}
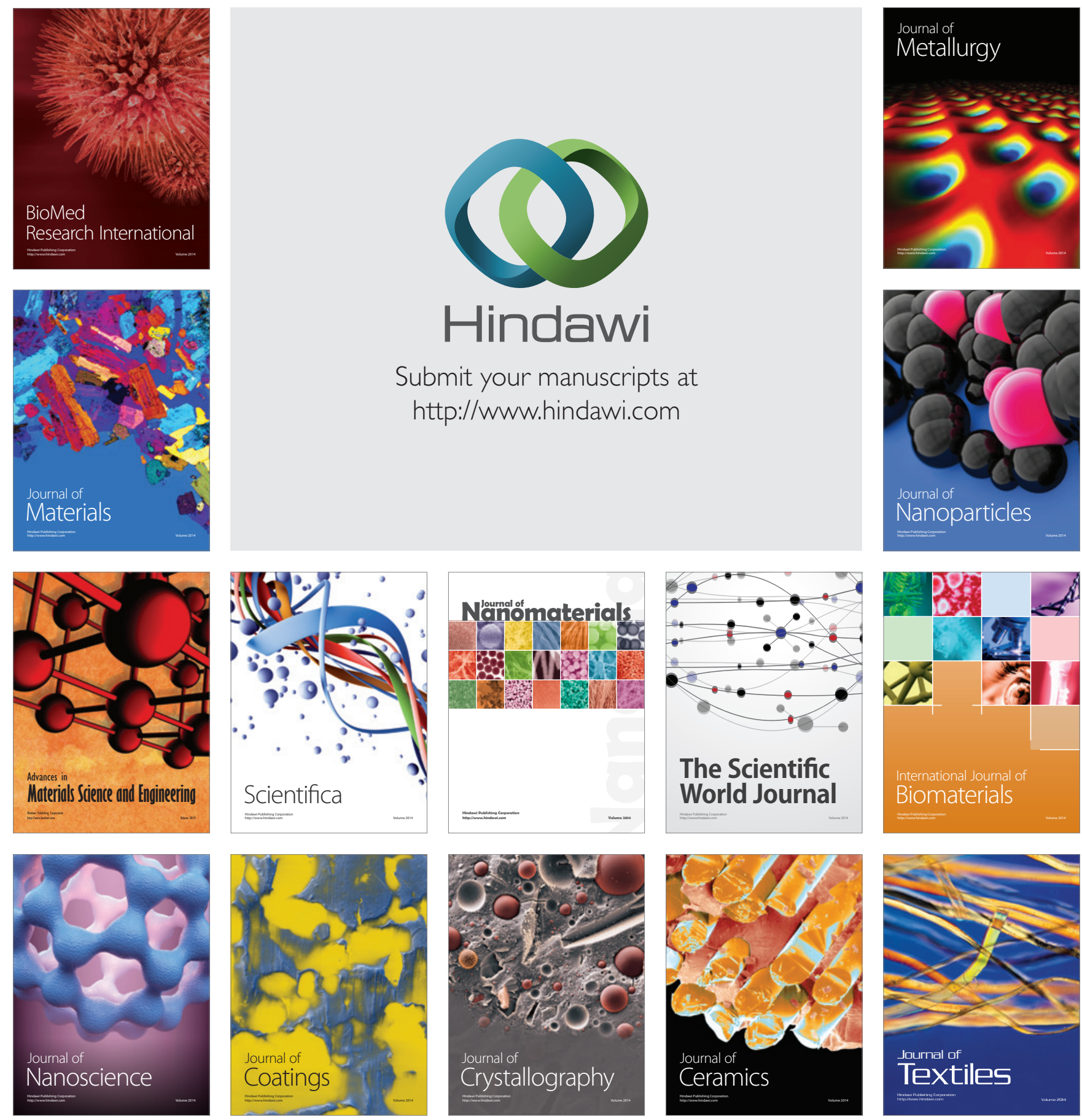